\title{
Uma interpretação das relações entre filosofia e teologia a partir da hermenêutica
}

Elton Vitoriano Ribeiro

Resumo

A teologia como hermenêutica da palavra de Deus e da existência humana é ato de interpretação do evento Cristo. Interpretação que acontece na relação entre a experiência cristã fundamental e a experiência humana hoje, e que prossegue numa dimensão de transformação da prática dos cristãos em vista de uma fé mais libertadora, caminhante na esperança, geradora de caridade. Minha reflexão neste artigo se desenvolverá em unidades concêntricas: a partir de uma abordagem mais abrangente sobre as relações entre filosofia e teologia, aprofundarei a questão hermenêutica e sua relação com a teologia. Para terminar, apresentarei a teologia hermenêutica iniciação ao mistério de Deus em nossas vidas. Mistério narrado nas Escrituras e nas vivências das comunidades cristãs, e interpretado em Igreja por homens e mulheres que fizeram de suas vidas uma adesão dinâmica e sempre renovada a Jesus Cristo.

Palavras-chave: Filosofia, Teologia, Hermenêutica

\section{Abstract}

Theology as Hermeneutics of the Word of God and human existence is an act of interpretation of the Christ event. Interpreting what happens in 
the relationship between the fundamental Christian experience and human experience today, and continuing transformation into a dimension of the practice of Christian faith in light of a more liberating walker in hope of generating charity. My reflection in this article will develop in concentric units: from a more comprehensive approach to the relations between philosophy and theology, hermeneutics delve into the issue and its relationship with theology. To conclude, I present the theology hermeneutics as initiation to the mystery of God in our lives. Mystery narrated in Scripture and in the experiences of Christian communities, and interpreted by the Church for men and women who made their lives a dynamic and constantly renewed adherence to Jesus Christ.

Keywords: Philosophy, Theology, Hermeneutics

Compreender a fé cristã é adentrar-se no mundo da interpretação, mundo da hermenêutica, mundo humano. A teologia como hermenêutica da palavra de Deus e da existência humana é ato de interpretação do evento Cristo. Interpretação que acontece na relação entre a experiência cristã fundamental e a experiência humana hoje, e que prossegue numa dimensão de transformação da prática dos cristãos em vista de uma fé mais libertadora, caminhante na esperança, geradora de caridade. Minha reflexão neste artigo se desenvolverá em unidades concêntricas: a partir de uma abordagem mais abrangente sobre as relações entre filosofia e teologia, aprofundarei a questão hermenêutica e sua relação com a teologia. Para terminar, apresentarei a teologia hermenêutica como mistagogia, ou seja, iniciação ao mistério de Deus em nossas vidas. Mistério narrado nas Escrituras e nas vivências das comunidades cristãs, e interpretado em Igreja por homens e mulheres que fizeram de suas vidas uma adesão dinâmica e sempre renovada a Jesus Cristo.

\section{As relações entre filosofia e teologia}

A teologia católica sempre defendeu a necessidade da reflexão filosófica como um momento interno da própria reflexão teológica ${ }^{1}$. Negar isto poderia

\footnotetext{
${ }^{1}$ Cf.: M. NÉDONCELLE, “Teologia e Filosofia ou as metamorfoses duma ancilla", Concilium, 6, 1965, 69-77. PP. JOÃO PAULO II. Carta Apostólica 'Fides et Ratio': sobre as relações entre fé e razão, São Paulo, Loyola, 1998. P. GILBERT, "Actualité d'une philosophie Chrétienne", Raison Politiques, nov. 2001, 1-7. A. GUGGENHEIM, "L'enseignement de la philosophie dans une Faculte de théologie", Nouvelle Revue théologique, 126, 2004, 412-419. M. A. OLIVEIRA, "É necessário filosofar na teologia:
} 
significar a própria negação da universalidade da revelação de Deus. Em última instância, terminar-se-ia por adotar uma posição fideísta, fundamentalista ou mesmo agnóstica. Assim, recorrer à reflexão filosófica significa procurar uma linguagem mais universal para falar sobre os dados da palavra revelada. Necessidade própria da revelação de Deus em Jesus Cristo apesar de sua particularidade sócio-histórica.

Nesta relação frutuosa da filosofia com a teologia, penso que a filosofia tem a missão de iluminar a fé com a luz da razão. Isto significa, entre outras questões, compreender o caráter histórico do conhecimento humano, apreciar e valorizar a solidão e o silêncio necessários a toda reflexão, dispor e estruturar a mente humana para o duro, sério e exigente labor teológico. Ainda, a filosofia apresenta seu valor para a reflexão teológica porque ela convida a pensar sempre mais. A filosofia convida a pensar precisamente ali onde outras disciplinas cessam seu discurso. Neste momento que a filosofia interroga, questiona. No momento onde as outras ciências oferecem uma resposta, a filosofia suspeita, duvida e pergunta mais, nunca satisfeita com uma solução particular para um problema específico. Eis a tarefa da filosofia.

Por outro lado, o caminho da filosofia é também o caminho da autoconsciência pessoal. A filosofia adentra-se nas questões fundamentais que caracterizam o próprio percurso da existência humana, com as quais a teologia também vai se deparar. Perguntas como quem sou eu? De onde venho e para onde vou? Porque existe o mal? O que existirá depois da vida? Estas e outras questões tocam no cerne da existência humana e do sentido da vida assim como a vivemos.

Além das questões existenciais, o caminhar filosófico é o caminhar à procura da verdade. Do ser humano, pode-se dizer, é aquele ser que procura, incansavelmente, a verdade. Diante desta questão ninguém pode, sinceramente, permanecer indiferente. Tanto é que na vida humana se descobrimos que algo é falso logo o rejeitamos, por outro lado, se descobrimos que algo é verdadeiro o acolhemos. Assim, indagar sobre a questão da verdade revelada em Jesus Cristo, tarefa da teologia, não poderá ser levada a cabo sem a companhia, questionadora e reflexiva, da filosofia.

unidade e diferença entre filosofia e teologia em Karl Rahner", Perspectiva Teológica, 36, 2004, 15-32. V. DÚRAN CASAS, "Filosofia ad maiorem Dei Gloriam", Gregorianum, 85/1, Roma 2004, 32-48. P. GILBERT, "Un cadet, un aîné, un fils unique" Revista Catalana de Teologia, XXXIII/1, 2008, 93-107. P. ROYANNAIS, "Penser philosophiquement la théologie", Recherches de Science Religieuse, JanvierMars 2010, 11-30. V. HOLZER, "Philosopher à l'intérieur de la théologie", Recherches de Science Religieuse, Janvier-Mars 2010, 59-84. PUTALLAZ, F. X., "De certains présupposés philosophiques aux chois herméneutiques", Revue Thomiste, Avril - Juin, 2010, 307-324. HUMBRECHT, T. D., "Interpréter l'herméneutique", Revue Thomiste, Avril - Juin, 2010, 325-341. 
De tudo o que disse parece-me claro que para a teologia, na sua elaboração reflexiva sobre a compreensão da palavra revelada, à luz da fé e no contexto atual, a filosofia deverá ser companheira sempre presente. Evidentemente, existe a questão sempre atual acerca do tipo de reflexão filosófica que estará sendo propícia à reflexão teológica. Quer dizer, que filosofia, que escola de pensamento, que autores ajudarão o teólogo no seu trabalho? Uma pista para tal questionamento encontro na Carta Apostólica Fides et Ratio de João Paulo II quando diz: "A palavra de Deus revela o fim último do homem, e dá um sentido global à sua ação no mundo. Por isso, ela convida a filosofia a empenhar-se na busca do fundamento natural desse sentido, que é a religiosidade constitutiva de cada pessoa. Uma filosofia que quisesse negar a possibilidade de um sentido último e global seria não apenas imprópria, mas errônea ${ }^{2}$ ".

Parece-me que uma filosofia radicalmente relativista, pragmatista ou niilista, seria inadequada à teologia. Uma filosofia de alcance ontológico, capaz de transcender os dados empíricos e partir em busca do absoluto e da abertura radical do ser humano ao transcendente é a que melhor desempenha a função de caminhar junto com a reflexão teológica. Nesta busca de uma reflexão filosófica que contribua à reflexão teológica, a hermenêutica tem sido uma das principais alternativas contra o fundamentalismo e o relativismo, como pretendo mostrar. Por isso, meu trabalho aqui será o de acompanhar a passagem da hermenêutica geral (filosófica), à hermenêutica particular (teológica) e aprofundar algumas reflexões que iluminem o trabalho teológico. A partir da filosofia defendo que é a hermenêutica, presente tanto na teologia quanto na filosofia, que permite construir um discurso, uma reflexão, que não trabalhe em regime de exceção, mas que tenha algo relevante a dizer aos homens e mulheres de nosso tempo.

\section{Uma narrativa da questão hermenêutica}

A palavra hermenêutica esteve sempre associada à arte de interpretar. Inicialmente foi compreendida como uma simples disciplina auxiliar, como um conjunto de regras para bem interpretar textos ${ }^{3}$. Etimologicamente, hermenêu-

\footnotetext{
${ }^{2}$ JOÃO PAULO II. Fides et Ratio, 81. Não tratarei aqui de questões que mereceriam uma atenta consideração como o respeito, necessário e frutífero, da autonomia do discurso teológico e filosófico, bem como do esclarecimento epistemológico entre o sentido último (filosófico) e sua nomeação cristã (teológico).

${ }^{3} \mathrm{Cf}$.: W. JEANROND, Introduction à l'herméneutique théologique - développement et signification, Paris, Ed. Du Cerf, 1995, 7-9.
} 
tica vem do verbo grego hermeneuein, do substantivo hermeneia, que geralmente foi traduzido por interpretação. Segundo Coreth ${ }^{4}$, a hermenêutica deve ser compreendida, num sentido mais amplo, como significar, declarar, anunciar, interpretar, esclarecer e traduzir, como tornar compreensível e conduzir à compreensão. Por outro lado, uma opinião que não encontra consenso entre os filólogos ${ }^{5}$, mas que ilustra admiravelmente a compreensão da palavra hermenêutica, diz respeito à associação hermenêutica ao deus grego Hermes. Hermes tinha por função trazer e traduzir as mensagens divinas para os seres humanos, ou seja, tinha como função fazer a hermenêutica das palavras dos deuses.

O emprego da palavra hermenêutica ganhou força no domínio teológico como arte da compreensão, como doutrina da boa interpretação no sentido utilizado pela interpretação das Escrituras, de uma interpretação correta e objetiva $^{6}$. Depois, a partir dos séculos XVII e XVIII, a palavra aparece empregada em outros campos do saber humano como a filologia e o direito, para citar dois exemplos. Porque a hermenêutica diz respeito à arte de interpretar, isto é, porque diz respeito à interpretação feita pelo ser humano, ela pode transformar-se num problema filosófico. Ao contrário da interpretação na literatura, na arte e no direito, que possuem um corpo de obras determinadas, a hermenêutica filosófica se interessa pelos princípios hermenêuticos da interpretação em si mesmos. Assim, pretendo agora discutir o percurso teórico moderno da formação da questão hermenêutica na filosofia começando por Schleiermacher.

Nos inícios do século XIX, Schleiermacher trabalha a idéia de uma hermenêutica universal ${ }^{7}$. A hermenêutica será apresentada por ele como uma disciplina que, perguntando pelas condições genéricas da compreensão do ser humano, deverá estabelecer as regras que permitem a compreensão objetiva. Compreensão objetiva não apenas de textos científicos setorizados, como por exemplo, textos religiosos, literários, jurídicos, mas de quaisquer pensamentos postos ao entendimento através de palavras. Desta forma, Schleiermacher aparece como o pai da hermenêutica moderna porque indaga pelas possibilidades da compreensão objetiva. Ele toma o primeiro passo em

\footnotetext{
${ }^{4}$ Cf.: E. CORETH, Questões fundamentais de hermenêutica, São Paulo, EPU/Edusp, 1973, 1.

${ }^{5}$ Cf.; J. GRONDIM, L'universalité de l'hermeneutique, Paris, Presses Universitaires de France, 1993, 10.

${ }^{6} \mathrm{Cf}$.: E. CORETH, Questões fundamentais de hermenêutica, 2. O debate sobre como se deve interpretar a Bíblia é anterior ao surgimento do conceito filosófico de hermenêutica evidentemente. Isto fica claro ao percebermos as várias escolas e correntes de exegese bíblica no antigo judaísmo, no que concerne à interpretação do Antigo Testamento.

${ }^{7}$ Cf.: F. SCHLEIERMACHER, Hermenêutica: arte e técnica de interpretação, Rio de Janeiro, Vozes, $1999,33$.
} 
direção a uma metodologia hermenêutica geral que é procurada no próprio ato de compreender. A interpretação, segundo Schleiermacher, deverá evitar o excesso da interpretação gramatical que leva ao pedantismo, e o excesso da interpretação psicológica que leva à nebulosidade ${ }^{8}$.

Para Schleiermacher, a interpretação será compreendida não meramente como uma questão de aplicar regras científicas. Ela será um ato criativo que sempre parte de uma idéia prévia, de uma intuição inicial, e nunca termina, mas permanece sempre como algo provisório. Por isso, não podemos compreender um texto sem o compararmos com outros semelhantes, e sem a intuição inicial a respeito da totalidade do texto para podermos compreender as partes. Há um círculo virtuoso entre o todo e as partes. Na construção reflexiva de Schleiermacher existe o elemento crítico de busca de superação de todo mal entendido, e o elemento romântico, do desejo de compreender o autor melhor do que ele compreendeu-se a si mesmo.

A reflexão filosófica sobre a hermenêutica de Dilthey ${ }^{9}$ assumirá grande parte das teses de Schleiermacher, direcionando-as, porém, rumo a uma fundamentação epistemológica das ciências do espírito. Dilthey irá propor a distinção entre ciências naturais, que trabalham com elementos a-históricos e busca explicá-los, e as ciências do espírito, que trabalha com elementos históricos e busca, por sua vez, compreendê-los. Assim, para Dilthey, a hermenêutica apresentaria métodos para se alcançar uma interpretação objetivamente válida das expressões da vida interior ${ }^{10}$. A hermenêutica seria o fundamento para as ciências do espírito. Isto porque, o que torna possível este compreender histórico é o fato de que o sujeito e o objeto são ambos históricos. Contra o romantismo de Schleiermacher, Dilthey levanta a tese de que não existe um acesso imediato à interioridade do outro. A compreensão tem, necessariamente, que passar pela interpretação das mediações, isto é dos signos, que expressam a vida ${ }^{11}$. Sendo assim, a vida pode ser compreendida graças ao que se expressa através dos signos, através da interpretação destes signos.

Heidegger rompe com as preocupações objetivantes anteriores. Ele vai radicalizar a experiência hermenêutica como um modo de ser do ser humano,

\footnotetext{
${ }^{8}$ Cf.: P. RICOEUR, Du Texte à l'action. Essais d'herméneutique II, Paris, Ed. Du Seuil, 1986, 78-80.

${ }^{9}$ Cf.: W. DILTHEY, Hermeneutics and the Study of History, New Jersey, Princeton University Press, 1996, 229-258.

${ }^{10}$ Cf.: R. PALMER, Hermenêutica, Lisboa, Ed. 70, 1997, 16.

${ }^{11}$ Cf.: P. RICOEUR, Du Texte à l'action, 81-87.
} 
realizando assim um giro ontológico na concepção de hermenêutica ${ }^{12}$. Desta forma, para Heidegger as coisas que se dão no mundo, não são compreendidas como que a partir de uma apropriação intelectiva do ser humano mediante a dicotomia sujeito-objeto. Invertendo a perspectiva são os fenômenos que implicam a potencialidade de se revelarem tal como são, independentemente de nosso subjetivismo. Por isso, a hermenêutica passa agora a significar uma fenomenologia da existência, uma análise das possibilidades que o ser tem de existir e de se manifestar através dos fenômenos que se dão no tempo. Para ele, a compreensão deixa de ser uma propriedade para se tornar um modo de existência, isto é, um elemento constitutivo do ser humano, um elemento anterior e mais profundo do que qualquer preocupação com a atividade interpretativa como tal. A hermenêutica alcança com Heidegger toda a radicalidade filosófica e passa a ser um problema ontológico. A compreensão é uma experiência ontológica universal. É importante ressaltar no pensamento de Heidegger a questão do círculo hermenêutico. O círculo hermenêutico é a estrutura antecipatória do próprio compreender. Assim, diante do absolutamente novo, sempre trato de compará-lo a algo já compreendido para poder interpretá-lo de alguma maneira. Desta forma, é o círculo hermenêutico que torna possível a interpretação.

Gadamer, perguntando pelo que significa compreender após as questões levantadas por Heidegger, isto é, buscando compreender o que seja a compreensão, retoma a discussão sobre a própria possibilidade da filosofia ${ }^{13}$. Em seu afã filosófico, ele vai dar um giro hermenêutico ao sustentar que a possibilidade da compreensão depende sempre da situação hermenêutica, isto é, do horizonte histórico em que encontra o sujeito que se põe a compreender. A compreensão depende sempre de um constante diálogo com a tradição que se faz presente no horizonte da pré-compreensão em que se forma, ontologicamente, a compreensão individual. Por isso, a hermenêutica, na concepção de Gadamer, não deve mais ser vista como um discurso sobre métodos de conhecimento objetivo, como era para Schleiermacher e Dilthey. Também não busca formular uma lista de regras interpretativas. Gadamer reflete sobre as condições de possibilidade da compreensão em geral. Compreensão enraizada em pré-conceitos e profundamente condicionada pelo passado. Gadamer quer libertar a hermenêutica da tentação iluminista

${ }^{12}$ Cf.: M. HEIDEGGER, Ser e Tempo, Petrópolis, Vozes, 15 ed, 2005, 68-69.

${ }^{13}$ Cf.: H.-G. GADAMER, Verdade e Método, Petrópolis, Vozes, 4 ed, 2002. H.-G. GADAMER, L'art de comprendre: hermeneutique et tradition philosophique, Paris, Aubier, 1982, 27-47. 
que oculta à compreensão ao esquecer a história, absolutizando o método. Para Gadamer, método não é caminho para verdade. Por isso ele não se preocupa com os problemas da formulação de princípios interpretativos corretos. Ele pretende esclarecer o próprio fenômeno da compreensão. Vale dizer, como é possível a compreensão, não só nas humanidades, mas em toda a experiência humana no mundo? Desta forma, o problema da hermenêutica é relativo à própria existência humana.

Gadamer aproveita de Heidegger a ideia de que não há compreensão sem pré-compreensão. Por isso, vai reabilitar em seu pensamento os conceitos de pré-juízo, autoridade e tradição, conceitos que haviam adquirido um significado pejorativo com a ideia, moderna, de um sujeito autônomo e emancipado de seu passado. Assim, a vinculação com a história é resgatada no fenômeno da compreensão, ou seja, toda compreensão é historicamente situada. Não que exista um determinismo da história, do passado. Para Gadamer, do passado, de alguma forma, é que depende os interesses que o presente guia à investigação histórica.

Neste percurso histórico que estou propondo o próximo pensador é Ricoeur. Ele vai chegar à reflexão hermenêutica a partir de seu projeto de abordar o problema do mal na existência humana. Para Ricoeur, a filosofia não chega pela pura reflexão à realidade do mal, mas ela precisa dar a volta, tomar o caminho longo da interpretação, da hermenêutica, pela linguagem simbólica com a qual o ser humano confessa o mal. Mas, a linguagem simbólica é opaca, tem duplo sentido, está situada numa determinada cultura particular e, sendo assim, sua interpretação é sempre questionável. Diante disso a filosofia tem que mudar seu método e converter-se em uma interpretação da linguagem simbólica, isto é, em hermenêutica. A hermenêutica buscará decifrar os níveis de significado ue se manifestam e ocultam nos símbolos ${ }^{14}$ e nas criações humanas ${ }^{15}$.

Para Ricoeur, a hermenêutica será um exercício de suspeita, de compreensão do ser através da interpretação da linguagem. Exercício que caminhará pela via longa e que deverá estar sempre em diálogo com as várias disciplinas que

\footnotetext{
${ }^{14}$ Importante lembrar que para Ricoeur os símbolos ao mesmo tempo em que revelam e manifestam, também ocultam. Esta questão é clara no pensamento dos mestres da suspeita (Nietzsche, Marx e Freud) que descobriram distintas maneiras em que, através dos símbolos, a consciência oculta, dissimula, mascara e falsifica o sentido. Por isso, o símbolo não se esgota numa única interpretação. O símbolo se apresenta como uma fonte inesgotável de possibilidades. Assim, o símbolo só funciona quando sua estrutura é interpretada. Quer dizer, necessitamos de uma hermenêutica mínima para que o símbolo funcione.

${ }^{15}$. Cf.: P. RICOEUR, Le conflit des interpretations, Paris, Ed. Du Seuil, 1969, 16-17.
} 
praticam a interpretação de uma maneira metódica. Por isso, ele vai realizar seu projeto num constante diálogo com a história, a exegese bíblica, a psicanálise, a poesia. Desta forma, Ricoeur estrutura a entrada da hermenêutica na filosofia em três etapas ${ }^{16}$. Primeiro a etapa semântica que se ocupa em definir os símbolos, os distintos métodos de interpretação e suas articulações. Depois, a etapa reflexiva que a partir da linguagem simbólica, critica a pretensão filosófica de fundar tudo no $\mathrm{eu}$. Finalmente, a etapa existencial que consiste em elaborar um pensamento filosófico acerca do ser do homem e do ser em geral. A partir desta reflexão, Ricoeur construirá uma hermenêutica textual onde o texto é entendido como produto de uma múltipla distanciação ${ }^{17}$ : (1) em relação à intenção do autor, (2) em relação às condições psicológicas e sociológicas de sua produção, (3) em relação à situação comum ao autor e os destinatários, e finalmente (4) em relação aos seus destinatários originais.

A distanciação, num primeiro momento reclama um método (análise estrutural) que recupera o significado objetivo e a referência do texto mesmo, isto é, desentranha a estrutura do texto. Num segundo momento reclama uma compreensão, onde o leitor vai expor-se ao texto, apropriar-se do significado do texto, receber do texto um novo si mesmo, onde o leitor re-contextualizará e atualizará para si mesmo e para seu presente o significado do texto.

A partir desta abordagem, Ricoeur provoca um deslocamento da reflexão hermenêutica. O primeiro deslocamento diz respeito à situação de oposição entre o explicar e o compreender. Ricoeur quer reconciliar verdade e método. Para isso, ele vai recolher de Heidegger a lição de despsicologizar o compreender histórico para o mundanizar; ou seja, a situação daquele que compreende em relação ao mundo precede o conhecimento do mundo como objeto. Ricoeur quer promover um tipo de leitura que renuncie de vez o desejo de alcançar um querer dizer do autor para ater-se à objetividade do texto. Como Gadamer, para Ricoeur, o que o leitor tem diante de si não é o autor, mas o mundo do texto, e a explicação será o caminho obrigatório da compreensão.

O segundo deslocamento diz respeito à questão da mediação do texto. Para Ricoeur o evento da palavra só existe no nível do discurso. Discurso que é sempre mensagem a respeito de alguma coisa. Ora, se à análise estrutural pertence à imanência do texto, ao discurso pertence o fazer advir um mundo, o mundo do texto. O discurso é que faz o evento da palavra permanecer

${ }^{16}$ Cf.: P. RICOEUR, Le conflit des interpretations, 14-24.

${ }^{17}$ Cf.: P. RICOEUR, Du Texte à l'action, 111. 
na forma de escritura. A escritura é a obra que assegura a função de mediação prática entre a palavra e o sentido. Desta forma o texto ganha vida própria, independente do autor e poderá ser lido em contextos diferentes, e consequentemente, suscitar múltiplas leituras.

Portanto, para Ricoeur o texto tem a pretensão de dizer alguma coisa sobre a realidade, ou seja, ele exprime certo mundo que ultrapassa o meramente linguístico e fenomenológico e toca numa ontologia da linguagem. $\mathrm{O}$ mundo do texto ou a coisa do texto é, propriamente, o mundo que o texto desdobra diante de $\mathrm{si}^{18}$. Segundo Geffré, "Ricoeur mantém distância de uma hermenêutica tradicional que acredita poder colher um sentido objetivo do texto, encontrando o querer dizer do autor. Mas ele guarda a distância também do estruturalismo, para o qual o sentido a compreender são as estruturas do texto e os mecanismos de seu funcionamento ${ }^{19}$ ".

Neste deslocamento provocado por Ricoeur é importante explicitar o lugar da relação entre a apropriação do texto e a compreensão de si. De um lado, apropriar-se do texto não é mais compreender o texto tornando-se contemporâneo da intenção do autor. Há uma autonomia em relação ao autor. Por outro lado, há também uma renúncia à pretensão da consciência de ser autofundadora e de estar na origem do sentido. Ora, o discurso consiste em que alguém diz alguma coisa sobre alguma coisa. Este sobre alguma coisa é uma função referencial inalienável do discurso. Nesta apropriação subjetiva do texto pelo leitor, compreender torna-se compreender-se diante do texto. Daí que hermenêutica será decifrar a vida no espelho do texto. Isto é possível porque o texto, assim como o símbolo, dá que pensar, para falarmos como Ricoeur. Mas, sobretudo, dá que viver. Dá que pensar porque dá que viver. É um pensamento que alimenta a vida e descobre a riqueza inesgotável da vida. Em torno de um texto lido um mundo se desdobra, mundo que é

\footnotetext{
${ }^{18}$ U. VASQUEZ - J. B. LIBÂNIO, "A Instrução sobre a Teologia da Libertação - Aspectos hermenêuticos," Perspectiva Teológica, 42, 1985, 151. Os autores explicitando esta questão dizem: "Como é conhecido, Paul Ricoeur situa seu projeto hermenêutico na trajetória filosófica que vai de Schleiermacher a Gadamer, passando por Dilthey e Heidegger. Para evitar as diversas aporias que se têm apresentado à hermenêutica ao longo da história da filosofia e que se resumem na antinomia explicar ou compreender e atualmente entre estruturalismo e interpretação ou entre crítica das ideologias e hermenêutica, Paul Ricoeur elaborou uma teoria hermenêutica que ele denomina 'centrada no texto'. Só a partir da efetuação de discurso como texto é possível superar o subjetivismo psicologista da hermenêutica romântica como também integrar a análise estrutural ou a crítica das ideologias como etapas necessárias ao processo hermenêutico. A explicação e a compreensão situam-se assim num único 'arco hermenêutico' que combina as duas atitudes opostas numa concepção global da leitura como retomada do sentido: é no próprio coração da leitura onde, indefinidamente, se opõem e se conciliam a explicação e a compreensão."

${ }^{19}$ C. GEFFRÉ, Como fazer teologia hoje: Hermenêutica Teológica, São Paulo, Paulinas, 1989, 50.
} 
proposto ao leitor para que ele o habite. E ao fazer sua habitação, o mundo do texto passa a tornar o mundo do leitor, onde ele compreende a si mesmo pela mediação do texto.

Mas a história não termina aqui. No debate filosófico atual, a hermenêutica é acusada, às vezes, de certo subjetivismo e relativismo, ou de um conservadorismo e uma submissão cega à tradição. Para alguns autores, a hermenêutica continua ligada ao pensamento metafísico ao buscar sempre "encontrar a inteligibilidade do ser sob o sensível ou de restaurar continuidade do sentido acima de distância cultural ou histórica ${ }^{20 "}$. Não pretendo entrar aqui no debate filosófico atual sobre o lugar da hermenêutica. Entendo ser importante retomar algumas considerações acerca do desenvolvimento da questão hermenêutica a partir do viés de Ricoeur que constrói seu pensamento:

1) trabalhando a questão da oposição entre explicar e compreender, a "explicação é um caminho obrigatório para a compreensão $0^{21}$, (2) trabalhando a questão da oposição entre distância e proximidade, pela mediação do texto um mundo desdobra-se diante do leitor ${ }^{22}$ e (3) trabalhando a questão da articulação entre a apropriação do texto e a compreensão de si, compreender é compreender-se diante do texto ${ }^{23}$.

A partir destas considerações anteriores, toda forma de compreensão é historicamente situada. O horizonte histórico de toda compreensão demonstra que o acesso do ser humano ao mundo se dá a partir de um ponto de vista determinado, de sua situação hermenêutica que é sempre um posicionar-se perante os fenômenos. É possível falar de um horizonte curto que supervaloriza o que está mais próximo, e de um horizonte mais largo que não se deixa limitar pelo que está mais próximo, mas busca ver para mais além. Logo, toda forma de compreender está enraizada na situação hermenêutica do sujeito. A própria compreensão é o modo de ser da existência humana no mundo, e sua possibilidade só se dá dentro do horizonte histórico.

O horizonte histórico é dinâmico e em constante formação. Desta forma, o ser humano, ao interpretar qualquer fenômeno já possui antecipadamente uma pré-compreensão do mesmo, isto é, um pré-conceito, uma antecipação de seu sentido influenciada pela tradição, pelas suas experiências, seu modo de vida, pela situação hermenêutica em que está inserido.

\footnotetext{
${ }^{20}$ C. GEFFRÉ, Como fazer teologia hoje, 31.

${ }^{21} \mathrm{P}$. RICOEUR, Du Texte à l'action, 137.

${ }^{22}$ Cf.: P. RICOEUR, Du Texte à l'action, 137-182.

${ }^{23}$ Cf.: P. RICOEUR, Du Texte à l'action, 183-211.
} 
Portanto, é possível concluir que a compreensão humana possui uma temporalidade intrínseca. Por isso, é importante tomar a sério a condição histórica de toda compreensão.

Neste compreender, o círculo hermenêutico é o momento estruturalmente ontológico da compreensão, na medida mesma em que caracteriza a estrutura de toda compreensão. O círculo hermenêutico ocorre no instante em que o sujeito, através de sua pré-compreensão, participa na construção do sentido do objeto, ao passo que o próprio objeto, no desenrolar do processo hermenêutico, modifica a compreensão do intérprete. Neste movimento de compreensão, o processo vai-se estabelecendo em patamares mais profundos de interpretação que, por sua vez, lançarão novas luzes sobre os pré-conceitos, e assim sucessivamente rumo a uma compreensão mais aprofundada. Segundo Coreth $^{24}$, o que temos é uma espiral hermenêutica. Nesta circularidade de compreensão entre o horizonte daquele que compreende com o horizonte em que adveio o objeto temos uma fusão de horizontes. Logo, a compreensão se dá como evento no momento em que há uma interação entre o mundo que se conhece e o mundo que se propõe a conhecer.

A compreensão ocorre sempre através de uma mediação em que o fenômeno nunca é visto em sua presença, mas sempre representado. Em toda atividade de compreensão, eu encaminho-me ao objeto com certo olhar. $\mathrm{O}$ objeto é por mim apreendido sob determinado foco e não na totalidade de seu sentido. Meu acesso ao objeto é sempre indireto. Eu chego a algo, mas enquanto algo. Não conheço o objeto em sua plenitude. Posso, assim, concluir que o mesmo evento ou o mesmo texto não é esgotável em sua plenitude de sentido. Ele pode ser compreendido e interpretado sob diversos aspectos, em várias relações ou direções de sentido. Isto é, há uma pluralidade de camadas de sentido. Por isso, tanto mais se alcançará o sentido pleno, quanto mais se levar em conta as várias camadas de sentido, integrando-as numa unidade. Esta integração, enquanto as maneiras de interpretar não se contradizem, não se excluem, mutuamente se completam.

Com isto não quero dizer que estamos à deriva, sem qualquer possibilidade de conhecimento das coisas. Apenas importa constatar que meu acesso a elas é sempre mediado, e que é através da mediação que posso alcançar a verdade. Esta verdade, este sentido, vem como revelação em virtude do jogo de velamento e desvelamento, de ocultação e desocultação. Ainda, a possibi-

${ }^{24}$ Cf.: E. CORETH, Questões fundamentais de hermenêtica, 90. 
lidade de acesso ao sentido das coisas é um caminhar por entre véus. É um constante projetar e reprojetar de sentidos. É um constante testar os meus pré-conceitos em face da própria presença do todo. Portanto, a atividade interpretativa é re-conhecimento que carrega sempre uma parcela de criação. $\mathrm{Na}$ finitude histórica de minha experiência sou consciente de que, depois de mim, outros compreenderão de maneira diferente. Sendo assim, o fenômeno da compreensão realiza-se numa fusão de horizontes na qual o mundo do objeto interpretado apresenta-se intermediado pela sua história. Quer dizer, pelo passado que chega através da tradição a que pertenço em uma fusão com meu horizonte atual. Também, a compreensão possui um caráter dialógico que se dá pela dialética da pergunta e resposta. Por isso, interrogar-se é abrir-se ao conhecimento.

O meio pelo qual ocorre à compreensão é a linguagem. É a linguagem que me abre ao mundo. É através dela que vivencio o mundo e nada existe para mim que seja exterior a ela. Na linguagem é o mundo do ser humano que é transmitido. É ele que existe por meio da linguagem; ou seja, é na linguagem que se dá a potencialidade humana do compreender o que é em si partilhado em vivências diversas e horizontes distintos. Assim, o que se compreende pela linguagem não é só uma experiência particular, mas é o mundo no qual a linguagem se revela.

\section{Interfaces entre hermenêutica e teologia}

Toda a minha argumentação até aqui foi uma tentativa de explicitar que o ser humano é um ser de linguagem. Na linguagem o ser humano vive e interpreta sua existência. Mais que um sistema de sinais, a linguagem é o evento de uma palavra que possui uma intencionalidade significante. Por isso, o ser humano sempre diz algo sobre algo. Como ser de linguagem o ser humano é interprete, faz hermenêutica, lê a vida no espelho do texto. Ora, se a interpretação é uma dimensão irrenunciável da existência humana, o discurso teológico também será interpretativo.

Para Geffré, a teologia é "hermenêutica da palavra de Deus e da existência humana ${ }^{25}$ ". Nesta afirmação há, evidentemente, um risco que é o próprio risco da interpretação. Mas, o risco de, por falta de audácia e lucidez, apenas se transmitir um passado morto não é menos grave do que o erro que se pode

${ }^{25}$ C. GEFFRÉ, Como fazer teologia hoje, 5. 
advir de uma interpretação incorreta. Para a teologia, urge correr o risco. Mas, este risco não é ingênuo ou desprovido de razões. É o risco da interpretação criativa que busca retomar, sem repetição, a mensagem cristã que só é fiel a si mesma à medida que gera novas figuras históricas na forma de práticas novas e libertadoras.

Assim, a teologia é, do começo ao fim, um empreendimento hermenêutico. Para falar como Schillebeeckx ${ }^{26}$ : "compreendo cada vez mais a função presente da teologia como correlação crítica e mútua entre a interpretação da tradição cristã e a interpretação de nossa experiência humana contemporânea ${ }^{27}$ ". Por isso, o ensinamento do teólogo deverá ser uma espécie de mediação entre o ensinamento magisterial da Igreja e a vivência irredutível do povo cristão. O teólogo possui a exigente vocação de propor práticas significativas para a Igreja, e será na prática dos cristãos que o teólogo encontrará o lugar teológico engendrado de dados para a interpretação criativa da fé.

Para mim, assumir o risco de interpretação no cristianismo é também reinterpretar sem cessar a boa nova da salvação à luz da experiência do sofrimento da humanidade. Sobre essa dimensão prática do cristianismo, penso que, em uma rápida análise de nosso mundo contemporâneo globalizado, é possível perceber uma injustiça estrutural que mata e faz sofre milhares de pessoas. Acredito que o cristianismo pode dar sua contribuição para a emergência de outro mundo. Mundo onde o ser humano seja respeitado em sua dignidade. Mundo onde a contemplação dos rostos humanos deve nos questionar sobre o chamado de Deus para uma humanização sempre maior. Certamente a teologia não dispõe de uma receita mágica para construir outro mundo mais justo e mais humano. Mas, a esperança cristã vive na certeza de que o Espírito de Deus está continuamente trabalhando para renovar, no coração humano, o desejo de transformação e vida. Por exemplo, Geffrée ${ }^{28}$ sugere aos cristãos uma purificação da memória sobre os erros do passado, um verdadeiro respeito e promoção do humano, uma busca de um mundo onde a lógica do amor gratuito, do perdão, da compaixão, da justiça estejam sempre a favor de todos, em especial dos mais desfavorecidos.

Penso ser importante esclarecer que a orientação hermenêutica é uma

\footnotetext{
${ }^{26}$ Vale ainda lembrar que para Schillebeeckx "não existe um conteúdo puro da fé, suscetível de uma formulação atemporal, independente do modus cum quo específico, que são as categorias historicamente limitadas de um tempo e lugar particular. O conteúdo dinâmico da fé é atingido somente numa interpretação nova e fiel, expressa em termos da nossa própria situação histórica concreta. A fé sempre se realiza como um entender interpretativo". Cf.: E. SCHILLEBEECKX, Cinco problemas que desafiam a Igreja de hoje, São Paulo, Herder, 1970, 15.

${ }^{27}$ Cf.: C. GEFFRÉ, Como fazer teologia hoje, p.7.

${ }^{28}$ Cf.: C. GEFFRÉ, “O Deus de Jesus e os possíveis da história”, Concilium, 308, 2004, 74-83.
} 
dimensão interior da própria razão teológica, isto é, uma maneira de se fazer teologia como leitura interpretativa de textos que é à maneira da teologia cristã desde as suas origens ${ }^{29}$. A razão teológica como razão hermenêutica terá que superar o apego à razão especulativa, entendida no sentido de conhecimento teórico, e buscar a aproximação à compreensão histórica ${ }^{30}$. A razão teológica trabalhará com os critérios de uma ciência hermenêutica no sentido moderno da palavra. Nesta perspectiva, fazer teologia é ter como ponto de partida o texto. Texto que está vinculado à tradição e a linguagem, a um horizonte de interpretação e a uma cultura. Texto que, segundo Tracy $^{31}$, manifesta sempre uma pluralidade de sentidos. Texto que resiste a uma interpretação que fecha, isto é, a uma interpretação que coloca fim a pluralidade de interpretações.

No caso da interpretação cristã, o teólogo irá utilizar-se da longa e rica tradição textual do cristianismo para poder aceder à experiência fundamental da salvação que nos é oferecida por Deus em Jesus Cristo. Desta forma, a interpretação hermenêutica cristã terá a tarefa de elucidar a experiência fundamental. Neste contexto é importante a compreensão da função da experiência, isto porque, o cristianismo não consiste numa mensagem que deva ser acreditada, mas, propriamente, numa experiência de fé que se traduz numa mensagem. Assim, estar em presença do horizonte de interpretação da tradição cristã é participar de um acontecimento vivo, dinâmico. Acontecimento inserido no coração da história e que será, por sua vez, lido numa dada situação histórica particular.

Ainda, a hermenêutica teológica não pode ser unicamente uma hermenêutica que procura simplesmente interpretar textos. Ela deve conduzir a certa prática eclesial, social, cultural e mesmo política. O teólogo responsável não se contentará apenas em propor novas e instigantes interpretações da mensagem cristã. Ele deverá levar a sério os sujeitos históricos concretos, conduzindo a certo fazer, isto é, a um buscar certas transformações da prática dos cristãos em vista do Reinado de Deus.

De toda a análise anterior assinalo alguns elementos importantes para a compreensão da tarefa teológica. A teologia passa cada vez mais a ter uma consciência de que a Palavra de Deus é testemunha da plenitude do Evangelho que é de origem escatológica ${ }^{32}$. Entendo que a Revelação não é comunicação

\footnotetext{
${ }^{29}$ Cf.: C. GEFFRÉ, Croire et interpréter. Le tournant herméneutique de la théologie, Paris, Du Cerf, $2001,7$.

${ }^{30}$ Cf.: C. GEFFRÉ. "Sentido e não-sentido de uma teologia não-metafísica”, Concilium, 6, 1972, 783-792.

${ }^{31}$ Cf.: D. TRACY, The Analogical Imagination, London, SCM Press Ltd, 1981, 408.

${ }^{32}$ Aqui entendo que o conteúdo essencial do Evangelho (da Boa Notícia) é o advento do Reinado de Deus na pessoa de Jesus Cristo: "Cumpriu-se o tempo, e o reinado de Deus aproximou-se: convertei-vos e crede
} 
de um saber fixado ${ }^{33}$. Ela é ação de Deus na história. História que é vivida e interpretada na experiência de fé do povo de Deus. Logo, toda Escritura já é interpretação e a Revelação atinge sua plenitude, seu sentido e sua atualidade somente na fé que a acolhe.

Ora, compreender a teologia como hermenêutica teológica é levar a sério a historicidade do ser humano como sujeito interpretante. Daí a possibilidade de dizer que a teologia é interpretação do significado atual do Evento Jesus Cristo a partir das diversas linguagens da fé suscitada por Jesus, por exemplo, presentes nos evangelhos ${ }^{34}$.

Importante ainda lembrar o papel da Tradição. O teólogo recebe o texto de uma comunidade, a Igreja. Uma comunidade que está em continuidade com a comunidade primitiva que produziu o texto. Desta forma, a leitura crente da Escritura é sempre leitura hermenêutica no sentido em que hoje interpretamos o texto dentro da mesma Tradição na qual ele foi escrito. A continuidade de sentido está atrelada à continuidade histórica. A referência à origem do sentido, a do evento fundador, é essencial. A transmissão desta mensagem não é mera repetição, ela é atualização sempre nova do que foi manifestado em Jesus Cristo.

Neste contexto hermenêutico, o objeto da teologia não é uma palavra originária, plena de sentido, da qual o texto seria apenas um eco. Também não é evento histórico descrito segundo os padrões modernos da historiografia. $\mathrm{O}$ objeto da teologia é um texto como ato de interpretação histórica e como nova estruturação hermenêutica do mundo. $\mathrm{O}$ texto remete a algo diferente dele. Remete a um tipo de mundo que possui alcance relevante para quem interpreta.

Algumas consequências desta reflexão. Em primeiro lugar, o objeto imediato do trabalho teológico não é uma série de proposições cuja inteligibilidade é procurada. É um conjunto de textos compreendidos no horizonte hermenêutico aberto pela revelação. A teologia, em seu labor para nomear Deus, deve res-

\footnotetext{
no evangelho" (Mc 1,15). Ou seja, o Reinado de Deus torna-se dinamicamente presente com e na pessoa de Jesus Cristo (Mt 12,28). Mas também, os discípulos recebem de Cristo a tarefa de continuar sua missão (Mt 28, 19-20; Jo 20, 21-23). Por isso, na era apostólica o evangelho é a obra da evangelização (1Cor 9, 14-18; F1 4, 3.15); é a própria mensagem pregada (Rm 1, 3-9.16); é toda a realidade cristã (Rm 1, 16). O Evangelho da pregação de Jesus torna-se, então, pregação sobre Jesus.

${ }^{33}$ Para Libânio, há um círculo hermenêutico entre dogma e escritura. Tanto um quanto outro dão testemunhos da plenitude da palavra de Deus, embora a escritura seja a autoridade última - norma normans non normata - em relação às novas escrituras que ela suscitou na Igreja. Cf.: J. B. LIBÂNIO, Eu creio, nós cremos, São Paulo, Loyola, 2000, 353-366.

${ }^{34}$ Cf.: R. J. JUNGES, Evento Cristo e Ação Humana, São Leopoldo, Ed. Unisinos, 2001, 89-130. C. PALÁCIO,

"Pressupostos teológicos para contemplar a vida de Jesus", ITAICI, 52, Junho 2003, 05-21.
} 
peitar a estrutura originária da linguagem da revelação e não reduzi-la, imediatamente, a um conteúdo proposicional ${ }^{35}$. Isto porque, a estrutura da confissão de fé está, inexoravelmente, ligada à estrutura da linguagem na qual se exprime ${ }^{36}$. O texto bíblico é revelação para nós porque ele desdobra um ser novo diante de nós e não porque teria sido escrito sob o ditado de Deus ${ }^{37}$. A apropriação do texto bíblico coincide não só com uma nova compreensão de si, mas também com uma nova possibilidade de existência ${ }^{38}$, com a vontade de fazer existir um mundo novo, ajudar na construção do reinado de Deus. Por exemplo, para Geffré, não há revelação sem conversão pessoal e inauguração de uma nova prática ética e social. A práxis cristã, a partir da teologia hermenêutica, é o lugar de produção da mensagem cristã. É, também, o lugar de verificação dessa mesma mensagem. É criadora de novas possibilidades de existência, desde que, se assuma o risco da interpretação, o risco de antecipar o futuro numa prática de esperança, alicerçada na fé, geradora de caridade. Por fim, a teologia diz sempre, numa diferença histórica, a verdade que lhe é confiada. Esta situação histórica a obriga a um constante ato de interpretação tanto na ordem da confissão, quanto na da prática que é parte integrante do mesmo ato de $\mathrm{crer}^{39}$.

Entendo ainda ser necessário dizer algumas palavras sobre a questão da tradição. Quem diz tradição não diz simplesmente transmissão de um dado válido em todos os tempos e lugares. A teologia vive de uma origem, o Evento Jesus Cristo como evento fundador. O novo testamento é testemunho deste evento fundador, não como um texto que nos é entregue imediatamente em seu

\footnotetext{
${ }^{35}$ Esta é uma discussão com a filosofia analítica. Para esclarecimentos ver: A. T. QUEIRUGA, Fim do Cristianismo pré-moderno. São Paulo, Paulus, 2003, 69-104.

36. Aqui é importante lembrar que, como nos ensina Ricoeur, a nomeação de Deus é polifônica, e é seguindo a particularidade própria de cada enunciado bíblico - que é inseparável de seu ato - que podemos elaborar uma teologia diversificada do nome de Deus. Ver: P. RICOEUR, "Nomear Deus", Nas Fronteiras da Filosofia, São Paulo, Loyola, 1996, 189-195.

${ }^{37}$ Aqui Geffré recorda a lição de Rahner de que Deus é o autor da escritura no sentido em que ele é autor da fé da Igreja primitiva, ou seja, aquele que reúne a comunidade, de cuja fé encontra sua expressão e sua objetivação na escritura. Ver: C. GEFFRÉ, Como fazer teologia hoje, 57. Também, neste mesmo sentido afirma a Dei Verbum (DV, III, 11) que "as coisas divinamente reveladas, que se encerram por escrito e se manifestam na Sagrada escritura, foram consignadas sob inspiração do Espírito Santo. (...) Escritos sob a inspiração do Espírito Santo (cf. Jo 20, 31; 2 Tim 3, 16; 2Ped 1, 19-21; 3, 15-16), eles têm Deus como autor e nesta sua qualidade foram confiados à mesma Igreja. Na redação dos livros sagrados Deus escolheu homens, dos quais se serviu fazendo-os usar suas próprias faculdades e capacidades, a fim de que, agindo Ele próprio neles e por eles, escrevessem, como verdadeiros autores (...)”. [grifo meu].

${ }^{38}$ É possível elucidar a questão dizendo que compreender-se diante do texto é não se entregar a uma compreensão puramente intelectual do texto, mas é tornar real uma nova possibilidade de existência e fazer, conseqüentemente, existir um mundo novo.

${ }^{39}$ Ato de crer que inclui um ato de compreensão que, por sua vez, repousa sobre pré-compreensões. Ato de compreensão que situa todo o trabalho de interpretação no interior de uma tradição interpretativa, consequentemente, situando assim, o ato de crer no interior do trabalho interpretante da comunidade cristã.
} 
sentido completo e definitivo. Ele é ato de interpretação, e a distância que nos separa deste evento é a condição de um novo ato de interpretação para nós hoje. Assim, na constituição da tradição cristã há, uma dialética de continuidade e ruptura. Nesta dialética, voltar para a origem é encontrar um ato que deve ser retomado de maneira sempre criativa e não repetido de maneira literal. Portanto, o cristianismo é tradição porque vive de uma origem primeira que é dada. Mas, ao mesmo tempo ele é produção, porque essa origem só pode ser redita historicamente numa interpretação criativa. Interpretação que por sua vez terá uma determinada recepção dentro de um contexto eclesial específico.

$\mathrm{Na}$ compreensão do pensamento teológico como aqui desenvolvi, a teologia será sempre um movimento contínuo de interpretação. Fazer teologia é inserir-se num movimento de interpretação, no círculo hermenêutico teológico. Círculo este que consiste na interdependência entre a interpretação sempre renovada da Escritura e Tradição e as novas perguntas suscitadas pela prática histórica. Desta forma, o círculo hermenêutico da teologia cristã é um círculo aberto a sempre novas atualizações de sentido. Atualizações onde a fidelidade às Escrituras e à Tradição cristã ${ }^{40}$, não fecham nem isolam o círculo, mas ao contrário, o obriga a sempre se abrir a novos horizontes de interpretação.

Por exemplo, o acontecimento pascal ${ }^{41}$ como narrado nos evangelhos, deve ser compreendido na dinamicidade do círculo hermenêutico. Ele não é um ponto de partida absoluto, mas se refere a uma história de fé que já é interpretada. História que proclama que Jesus é o Messias. Mas, a palavra messias, dentro da expressão Jesus Cristo, adquire sempre um significado para quem a interpreta. Significado que é fruto da obra de infinitas retomadas de sentido que não cessam de colocar o crente na dinâmica hermenêutica de compreender sua existência cristã à luz do acontecimento pascal ${ }^{42}$. E, na medida mesma em que o crente avança na escuta do texto, ele vai corrigindo, isto é, modificando sua pré-compreensão.

\footnotetext{
${ }^{40}$ Evidentemente, ao falar de Tradição cristã sempre fica a questão acerca do discernir os aspectos evangélicos dos aspectos eclesiásticos. Este tema não o desenvolvo aqui, vale lembrar que, segundo a Dei Verbum (DV, II, 7-8) a Tradição é um dom que é transmitido e que se insere em um processo histórico que garante o seu progresso. Também, Escritura e Tradição brotam da própria fonte divina, mantêm uma ligação e uma comunicação mútua. A Escritura é a Palavra de Deus por ter sido escrita por inspiração, e esta é transmitida integralmente pela Sagrada Tradição (DV, II, 9).

${ }^{41}$ Cf.: C. PALÁCIO, "Que significa crer em Jesus Cristo hoje? Preâmbulos para uma fé sensata e responsável", Rev. Horizonte, n.1, 1997, 41-54.

${ }^{42}$ Para uma poética e brilhante elucidação sobre esta questão ver a argumentação de L. Boff em "A Estrutura pascal da existência humana - A Paixão, a Morte e a Ressurreição na vida de cada pessoa”, em: L. BOFF, Via Sacra da Ressurreição, Petrópolis, Vozes, s/d, 09-26.
} 
A partir deste caminho hermenêutico que estou apresentando, pode surgir a questão acerca da possibilidade de re-interpretar a unidade cristã sem negar a abertura a novidade e a diversidade presentes historicamente no coração da fé, ou seja, a relação da unidade cristã com a pluralidade de vivências da fé cristã. Ora, para elucidar tal questão eu penso que se deve partir da referência única ao Evento Cristo. A maneira cristã de viver a fé encontra sua referência última no acontecimento Jesus confessado como o Cristo. Em regime cristão o critério de discernimento de toda autocomunicação de Deus é Jesus Cristo. Cristo é a norma última da fé cristã.

$\mathrm{Na}$ dinamicidade característica da teologia como hermenêutica, penso ser possível vislumbrar traços de um caminho de reflexão que poderá ajudar a correr o risco da interpretação. O ponto de partida será o da pluralidade de testemunhos presentes dentro do campo hermenêutico aberto pelo Evento Cristo. Estes primeiros testemunhos são atos de interpretação das primeiras comunidades cristãs suscitados sob a ação do Espírito Santo. Ação que também se faz presente na história da experiência de fé da Igreja. Assim, a teologia como hermenêutica será sempre "um novo ato de interpretação do Evento Cristo na base da correlação crítica entre a experiência cristã fundamental, testemunhada pela tradição e a experiência humana de hoje $\mathrm{e}^{43}$ ".

Desta argumentação que venho conduzindo, penso que o caminho hermenêutico, caminho de interpretação inerente ao ato de intelecção da fé, deve apresentar as seguintes relações entre os três modos de tempo próprios da história. O passado é visto como memória crítica, como lugar gerador da pré-compreensão própria de todo ato de interpretar. O presente é o momento de compreender a experiência humana à luz da palavra de Deus. O futuro é o horizonte da promessa de realização da palavra.

Neste movimento hermenêutico, alguns critérios ajudam a pautar o caminho. Primeiro os critérios linguísticos que são critérios que dizem respeito ao sentido de todo enunciado. São os recursos analíticos-linguísticos aplicados à hermenêutica teológica. As reflexões advindas das ciências da linguagem, do estruturalismo, da fenomenologia da linguagem, da filosofia analítica e da ontologia da linguagem. Segundo, os critérios teológicos que são os critérios que dizem respeito à questão do sentido e da verdade do enunciado teológico. Trabalham diretamente com a experiência cristã, são eles a Escritura ${ }^{44}$, a

${ }^{43}$ C. GEFFRÉ, Como fazer teologia hoje, 68.

${ }^{44}$ Não tratarei aqui da importante questão da hermenêutica bíblica. Para tal esclarecimento ver: U. SCHNELLE, Introdução à Exegese do Novo Testamento, São Paulo, Loyola, 2004, 151-182. PONTIFÍCIA 
Tradição, a Ortopráxis cristã, o Consensus Ecclesiae, e o Magistério. Por fim, o critério pastoral ou de atualização que trata da relação entre o enunciado e a experiência, entre a pergunta humana e a resposta da revelação. É um critério de preocupação pastoral, onde as fórmulas e enunciados devem ser respostas a perguntas feitas hoje. Este critério quer salvar a atualidade da palavra de Deus em cada momento. Portanto, este possível caminho que apresento, poderá ajudar a traçar uma rota de investigação e elucidação dos círculos hermenêuticos da reflexão teológica.

\section{Conclusão}

Tentei apresentar um percurso de interpretação das relações entre filosofia e teologia a partir da questão hermenêutica. Eu não poderia terminar sem argumentar brevemente acerca da atual produção teológica que se encontra em um horizonte de reflexão plural, rico em formas de vida, expressões culturais e maneiras de compreensão da dimensão religiosa do ser humano. Nesta multiplicidade, a tarefa da teologia de dar razões de nossa esperança (1Pd $3,15)$ continua desafiante e necessária.

Penso que nesta pluralidade o ato cristão não se situa num vazio conceptual. A própria reviravolta provocada pelo pensamento hermenêutico permite falar de uma proposta para a teologia que não caia num dogmatismo estéril, nem num fideísmo paralisante. Para a hermenêutica teológica, falar de Deus é também falar do ser humano que fala de Deus. É um falar que deve manifestar a pertinência do mistério cristão para a inteligência e a prática dos homens e das mulheres contemporâneos. Assim, a fé cristã proclama que o mandamento do amor a Deus é semelhante ao mandamento do amor ao próximo. Fé cristã que se compreende nos seguimento e adesão a uma pessoa: Jesus Cristo. Então, o ponto de partida da teologia será sempre um evento concreto, ou seja, o evento da revelação cumprida e realizada em Jesus Cristo. Por isso, a teologia deve ser compreendida como um interpretar a escritura da revelação de Deus na história, dentro de uma tradição, atualizando-a para os homens e mulheres de hoje. A teologia é hermenêutica atualizante da palavra de Deus e da existência humana.

Assim, quando lemos as Escrituras, quando re-lemos as nossas experiências de vida, quando nos defrontamos com estes textos com simpatia,

COMISSÃO BíBLICA. A Interpretação da Bíblia na Igreja. São Paulo, Paulinas, 1994, 87-88. 
imaginação e amor, para falar como Ricoeur, que vão fazendo e re-fazendo nosso horizonte, nos defrontamos com a questão da intriga. A intriga, segundo Lévinas $^{45}$, é a relação entre os termos onde um e outro não são unidos nem por uma síntese do entendimento, nem pela relação do sujeito ao objeto e, no entanto, um é imprescindível ou é significante para o outro, sendo que eles estão ligados entre si sem que o saber possa esgotá-los ou desvelá-los. Ora, eu entendo que interpretar a Escritura, interpretar as experiências de vida à luz da Escritura, para agir com sentido, é um ato inesgotável de intriga, assim como é inesgotável a maravilha e a novidade da ação humana inspirada pelo Espírito de Deus. O interpretar, o ler dá-se na relação de intriga onde o aproximar-se da Escritura, é um ir-se configurando, numa verdadeira fusão de horizontes, ao Cristo Jesus. Configuração que ao apresentar um modelo de humanidade, interpela nossa própria humanidade a um agir com sentido, no mundo, com os outros. É um passar do texto à ação e da ação ao texto, neste círculo virtuoso que é o compreender-se (compreender a vida) iluminados pela Palavra de Deus.

No final destas reflexões pergunto: como traduzir para os homens e as mulheres contemporâneos a fé cristã? Fé cristã que é fundamentalmente experiência da misteriosa gratuidade de Deus. Gratuidade que se revela na encarnação onde se opera uma transformação radical do imaginário a respeito da onipotência divina, que se transforma em certa impotência diante da história. Fé cristã que nasce de um ato de interpretação, feita pela primeira comunidade cristã, do Evento Jesus Cristo como evento de salvação da parte de Deus para nós.

Este desafio, assim eu entendo, deve ser enfrentado partindo da experiência humana de busca de sentido. Isto porque, a pergunta humana neste mundo é pergunta pelo sentido da realidade e da existência. Assim, a fé cristã se apresenta como uma resposta humana que tenta articular um sentido único e definitivo, mas o qual só se atinge mediatizado pela interpretação na comunidade daqueles que crêem. Esta interpretação produz uma resposta humana que, ao se tornar teologia, fala de Deus a partir da humanidade e divindade de Jesus Cristo. O método para tal teologia será o hermenêutico porque ele corresponde à natureza mesma da palavra de Deus - que é escritura de um testamento interpretado - e da fé cristã. Por este motivo a verdade revelada não será nunca uma verdade morta, mas sempre uma verdade viva, sempre transmitida numa mediação histórica e que precisa ser atualizada sem cessar.

Penso que, todo trabalho da hermenêutica teológica será o da interpreta-

${ }^{45}$ Cf.: E. LÉVINAS, En découvrant l'existence avec Husserl et Heidegger, Paris, Libraire J. Vrin, 1988, 255. 
ção. Interpretação que quer fazer emergir desse encontro um sentido que leve o crente a uma práxis em favor dos outros, como maneira de atualizar a experiência de fé. Esta atualização é acompanhada de uma celebração do mistério de Deus em nossas vidas. É a dimensão celebrativa, litúrgica. Liturgia que no seu constante repetir de gestos, orações e louvores, conduz a experimentar o mistério de Deus em nossas vidas. Experiência de fé que é vivida sob o signo da adesão pessoal e comunitária a uma pessoa que não pode ser decifrada, mas que convida ao seu seguimento na história.

Desta forma fica claro que a fé cristã é, fundamentalmente, aderir a Jesus Cristo. Não é um objeto de uma doutrina racional, mas é, no seu aspecto dinâmico e existencial um seguir a Jesus Cristo na história. Por isso, o específico da revelação cristã é o dom misterioso que Deus faz de si mesmo aos homens e mulheres. Dom que é dado, não através da comunicação de verdades e segredos, mas através do dom último de uma pessoa: Jesus, o Cristo. Portanto, para a hermenêutica teológica, a Escritura Cristã é compreendida como fruto do diálogo entre Deus e o ser humano. Diálogo onde Cristo é o mediador absoluto, que nos revela por seu Espírito que somos todos filhos de Deus e irmãos uns dos outros.

\section{Referências Bibliográficas}

BOFF, L., Via Sacra da Ressurreição, Petrópolis, Vozes, s/d.

CORETH, E., Questões fundamentais de hermenêutica, São Paulo, EPU/ Edusp, 1973.

DILTHEY, W., Hermeneutics and the Study of History, New Jersey, Princeton University Press, 1996.

DÚRAN CASAS, V., "Filosofia ad maiorem Dei Gloriam", Gregorianum, 85/1, Roma 2004, 32-48.

GADAMER, H.-G., L'art de comprendre: hermeneutique et tradition philosophique, Paris, Aubier, 1982.

, Verdade e Método, Petrópolis, Vozes, 4 ed, 2002.

GEFFRÉ, C., "Sentido e não-sentido de uma teologia não-metafísica", Concilium, 6, 1972, 783-792.

, Como fazer teologia hoje: Hermenêutica Teológica, São Paulo, Paulinas, 1989.

, Croire et interpréter. Le tournant herméneutique de la théologie, Paris, Du Cerf, 2001. 
, "O Deus de Jesus e os possíveis da história", Concilium, 308, 2004, 74-83.

GILBERT, P., "Actualité d'une philosophie Chrétienne", Raison Politiques, nov. 2001, 1-7.

, "Un cadet, un aîné, un fils unique" Revista Catalana de Teologia, XXXIII/1, 2008, 93-107.

GRONDIM, J., L'universalité de l'hermeneutique, Paris, Presses Universitaires de France, 1993.

GUGGENHEIM, A., "L'enseignement de la philosophie dans une Faculte de théologie", Nouvelle Revue théologique, 126, 2004, 412-419.

HEIDEGGER, M., Ser e Tempo, Petrópolis, Vozes, 15 ed, 2005.

HOLZER, V., "Philosopher à l'intérieur de la théologie", Recherches de Science Religieuse, Janvier-Mars 2010, 59-84.

HUMBRECHT, T. D., "Interpréter l'herméneutique”, Revue Thomiste, Avril - Juin, 2010, 325-341.

JEANROND, W., Introduction à l'herméneutique théologique développement et signification, Paris, Ed. Du Cerf, 1995.

JOÃO PAULO II. Carta Apostólica 'Fides et Ratio': sobre as relações entre fé e razão, São Paulo, Loyola, 1998.

JUNGES, R. J., Evento Cristo e Ação Humana, São Leopoldo, Ed. Unisinos, 2001.

LÉVINAS,E., En découvrant l'existence avec Husserl et Heidegger, Paris, Libraire J. Vrin, 1988.

LIBÂNIO, J. B., Eu creio, nós cremos, São Paulo, Loyola, 2000.

NÉDONCELLE, M., "Teologia e Filosofia ou as metamorfoses duma ancilla", Concilium, 6, 1965, 69-77.

OLIVEIRA, M. A., "É necessário filosofar na teologia: unidade e diferença entre filosofia e teologia em Karl Rahner", Perspectiva Teológica, 36, 2004, 15-32.

PALÁCIO, C., "Que significa crer em Jesus Cristo hoje? Preâmbulos para uma fé sensata e responsável", Rev. Horizonte, n.1, 1997, 41-54.

, "Pressupostos teológicos para contemplar a vida de Jesus", ITAICI, 52, Junho 2003, 05-21.

PALMER, R., Hermenêutica, Lisboa, Ed. 70, 1997.

PONTIFÍCIA COMISSÃO BÍBLICA. A Interpretação da Bíblia na Igreja.

São Paulo, Paulinas, 1994. 
PUTALLAZ, F. X., "De certains présupposés philosophiques aux chois herméneutiques", Revue Thomiste, Avril - Juin, 2010, 307-324.

QUEIRUGA, A. T., Fim do Cristianismo pré-moderno. São Paulo, Paulus, 2003.

ROYANNAIS, P., "Penser philosophiquement la théologie", Recherches de Science Religieuse, Janvier-Mars 2010, 11-30.

RICOEUR, P., Le conflit des interpretations, Paris, Ed. Du Seuil, 1969. , Du Texte à l'action. Essais d'herméneutique II, Paris, Ed. Du Seuil, 1986.

, Nas Fronteiras da Filosofia, São Paulo, Loyola, 1996.

SCHILLEBEECKX, E., Cinco problemas que desafiam a Igreja de hoje, São Paulo, Herder, 1970.

SCHLEIERMACHER, F., Hermenêutica: arte e técnica de interpretação, Rio de Janeiro, Vozes, 1999.

SCHNELlE, U., Introdução à Exegese do Novo Testamento, São Paulo, Loyola, 2004.

TRACY, D., The Analogical Imagination, London, SCM Press Ltd, 1981.

VASQUEZ, U., - LIBÂNIO, J. B., "A Instrução sobre a Teologia da Libertação - Aspectos hermenêuticos," Perspectiva Teológica, 42, 1985, 151.

Elton Vitoriano Ribeiro Doutor em Filosofia Professor de Filosofia na FAJE: Faculdade Jesuíta de Filosofia e Teologia e-mail: eltonvitoriano@gmail.com

Artigo Recebido em 26/04/2011 Artigo Aprovado em 23/06/2011 